\title{
PERCEPÇÃO DA ÉTICA CONTÁBIL: UM ESTUDO EMPÍRICO COM DISCENTES DO CURSO DE CIÊNCIAS CONTÁBEIS
}

\author{
ARTIGO ORIGINAL \\ QUEIROZ, Mariana Santos De ${ }^{1}$ \\ PIRES, Pedro Guilherme Siqueira de Sousa ${ }^{2}$ \\ MAZZER, Lílian Perobon ${ }^{3}$
}

QUEIROZ, Mariana Santos De. PIRES, Pedro Guilherme Siqueira de Sousa. MAZZER, Lílian Perobon. Percepção da ética contábil: Um estudo empírico com discentes do curso de Ciências Contábeis. Revista Científica Multidisciplinar Núcleo do Conhecimento. Ano 05, Ed. 01, Vol. 06, pp. 107-130. Janeiro de 2020. ISSN: 2448-0959, Link de acesso: https://www.nucleodoconhecimento.com.br/contabilidade/percepcao-daetica-contabil

\section{RESUMO}

Esta pesquisa teve por objetivo investigar a percepção que os discentes do curso de Ciências Contábeis têm sobre a Ética Contábil. O trabalho foi desenvolvido por uma metodologia conduzida através de uma pesquisa exploratória, descritiva, documental e bibliográfica por meio de um levantamento realizado com 204 estudantes públicas e privadas de nove estados brasileiros, sendo eles, Bahia, Ceará, Espírito Santo, Maranhão, Paraíba, Pernambuco, Piauí, Rio Grande do Sul e Santa Catarina. Onde os dados foram coletados através de um questionário estruturado em quatro sessões. Como resultados, a pesquisa identificou que os discentes percebem a importância da

\footnotetext{
${ }^{1}$ Graduanda em Ciências Contábeis.

${ }^{2}$ Graduando em Ciências Contábeis.

${ }^{3}$ Doutora em Ciências Contábeis.
} 
Ética para sua futura profissão, e que os mesmos dão importância ao código de ética do contador. Analisou-se que grande parte dos discentes quando deparados com exemplificações do cotidiano agiriam de forma ética na maioria dos casos.

Palavras-chaves: Ética Contábil, percepção, discente.

\section{INTRODUÇÃO}

Desde os primórdios da humanidade, das civilizações nômades, quando as sociedades começaram a surgir, se fez necessário o surgimento de regras de convivência para regular as relações entre os indivíduos, mesmo estas sendo rústicas, eram necessárias para uma convivência pacífica, que devido a cada um carregar consigo seus ideais e ter pensamentos desiguais, surgiam dilemas no meio do caminho, dessa maneira as pessoas baseiam-se nos princípios da Ética e da Moral para garantir o bem-estar de todos e a uma relação harmônica entre os indivíduos.

Geralmente as palavras Ética e Moral são utilizadas como sinônimas, porém existem diferenças na definição desses conceitos, já que a Ética é um ramo da filosofia, que analisa o lado científico e racional dos atos morais, enquanto moral está relacionado com os hábitos, costumes e tradições de uma determinada sociedade.

Vásquez (1989), diz que a ética seria a ciência do comportamento humano em sociedade, ou seja, apresenta caráter científico, já Oliveira et. al. (2010, p. 23) define moral como "conjunto de normas, princípios, preceitos, costumes, valores que norteiam o comportamento dos indivíduos no seu grupo social".

Como elas estão intimamente relacionadas é comum que haja esse equívoco em relação ao uso da nomenclatura desses termos. É importante que os princípios éticos e morais, se façam presentes em todos os tipos de relações desde a familiar até o profissional, grande parte das profissões elaboram o seu próprio Código de Ética, estes normatizam e definem as condutas esperadas pelos profissionais, além de multas e punições caso não cumpram o que foi estabelecido. 
Como o profissional Contábil tem uma importante função perante a sociedade, é imprescindível que ele preze pelos bons princípios éticos, como honestidade, transparência, zelo e decoro, pois não irá faltar ocasiões que atentem contra os seus valores. De acordo com Feil et.al (2017) na contabilidade, além da educação ética, fatores individuais, como gênero, idade, experiência profissional, religiosidade, etnia e nível educacional, também podem influenciar a conduta ética.

Na profissão Contábil, o Código de ética da profissão (CEPC) , foi instituído em 1996 através do decreto no 803 , pelo Conselho Federal de Contabilidade que tem o objetivo principal de fixar a forma pela qual se deve conduzir os Profissionais da Contabilidade, quando no exercício profissional e nos assuntos relacionados à profissão e à classe (CÓDIGO DE ÉTICA PROFISSIONAL DO CONTADOR, 1996).

Nas instituições de ensino superior, a ética é fundamental no processo de formação dos futuros profissionais, pois através dela os discentes compreenderão o impacto da ética em seus negócios, e quais serão os riscos assumidos, caso eles apresentem condutas antiéticas. De acordo com Silva e Figueiredo (2012) a educação formal nas instituições de ensino superior, desenvolve reflexões sobre os conceitos de Ética e contribui para desenvolver, entre os futuros profissionais, a percepção da necessidade do agir ético.

Diante do exposto, propõe-se um estudo para pesquisar a seguinte questão: Qual a percepção que os discentes do curso de Ciências Contábeis têm sobre a Ética contábil?

Logo, esta pesquisa tem o objetivo geral de investigar a percepção que os discentes do curso de Ciências Contábeis têm sobre a Ética Contábil. Para alcançá-lo, foram traçados os seguintes objetivos específicos: (i) apresentar o perfil dos discentes, (ii) identificar a percepção da Ética geral e possíveis contextos do cotidiano e (iii) analisar suas ações com possíveis estudo de casos.

A relevância da pesquisa justifica-se por analisar e investigar a percepção sobre ética geral, e o CEPC, para que os estudantes de graduação, conheçam a importância 
desse assunto na sua formação, além de contribuir cientificamente com outras pesquisas nessa área. Lisboa et.al (1996) dizem que não basta ao profissional a preparação técnica, mas tem que ter uma finalidade social superior nos serviços que executa, defendendo os princípios e valores éticos da profissão, de tal forma a produzir uma imagem verdadeira do que ela se constitui. Com objetivo de contribuir com o tema tratado, são apresentados alguns estudos relacionados ocorridos anteriormente, destacam-se os realizados por Alves (2005); Antonovz et al (2010); Martins e Benck (2018).

A contribuição deste estudo se relaciona ao avanço do conhecimento empírico sobre o tema, pois, ao constatar as inclinações e as variáveis intervenientes que influenciam as atitudes dos estudantes, pode-se atuar preventivamente para intensificar a consciência ética, objetivando evitar futuros desvios de conduta do profissional contábil. Além disso, os órgãos de classe, com o auxílio desses resultados, podem formalizar eventos alinhados para dirimir as carências. Com essas contribuições, os futuros profissionais poderão estar mais bem preparados para atuar de forma honesta e transparente, aumentando, assim, a credibilidade da informação gerada pela prática contábil e gerando reflexos positivos para toda a sociedade.

Este artigo está organizado em 5 seções, onde a primeira apresenta a contextualização acerca da temática estudada seguida pelos seus objetivos e justificativa da pesquisa; já a segunda parte, apresenta o referencial teórico, no qual aborda tópicos sobre Ética e Moral, Ética profissional e contábil, CEPC, na terceira seção, está presente os procedimentos metodológicos que auxiliaram a pesquisa; a quarta evidência a análise e discussão dos dados da pesquisa e por fim, apresentase as considerações finais. 


\section{REFERENCIAL TEÓRICO}

\section{1 ÉTICA GERAL}

A ética pode ser entendida como a ciência que estuda a conduta dos seres humanos, ou seja, é a ciência específica do comportamento humano (BARRETO, 2015). Ainda segundo o mesmo autor, a moral conceitua-se como o conjunto de costumes, normas e regras que a sociedade impõe. De acordo com Alves (2005, p. 17) “A Ética se dedica ao estudo dos princípios morais que orientam os grupos humanos em diferentes contextos, a Moral corresponde a um conjunto de regras assumidas pelos membros de um determinado grupo social".

Segundo os autores Berlatto et al (2015) e Cruz et al (2018), ética pode ser considerada como ciência, e esta estuda o comportamento humano, sempre olhando o bem no geral, tanto coletivo como individual.

Segundo Corrêa et al (2005)

A ética é a maneira pela qual se pode verificar se as regras morais de uma sociedade estão corretas ou não, ela na sociedade pode ser estudada como: a ciência que estuda a conduta do ser humano ou, ainda, como a ciência que busca os modelos de conduta convenientes ao ser humano.

Alguns comportamentos que antes eram aceitos pela sociedade, com o passar do tempo podem ser condenados, do mesmo jeito que pode ocorrer o inverso. Conforme Silva et al (2015) a ética é a ferramenta pela qual pode-se analisar as regras da sociedade no geral, e a partir disso, classificar em "certo" ou "errado".

\section{2 ÉTICA PROFISSIONAL E CONTÁBIL}

Toda e qualquer profissão deve manter padrões éticos elevados, para que assim possa realizar o seu papel social de maneira aprazível, e atingir respeito 
e credibilidade perante seus colegas, e a sociedade na qual está inserido, e com a profissão contábil, não seria diferente, conforme argumenta Alves (2005), a classe contábil necessita manter elevados padrões éticos junto à sociedade, como requisito essencial para a sua própria existência. Desde o começo de sua construção, o profissional deve entender que por maior que seja seu conhecimento técnico, ele jamais virá a ser um profissional respeitado, caso não preze seu lado ético (Barreto, 2015).

Conforme Feil et al (2017) a importância da ética profissional vincula-se à proteção dos profissionais e clientes, uma vez que esclarece as responsabilidades do profissional e aperfeiçoa seu perfil. De acordo com Alves (2005) ética profissional pode ser considerada como uma parte da ética que relaciona os mandamentos básicos da relação do trabalho.

Segundo Alves (2005) o surgimento da ética nas empresas nasce como um instrumento imposto pela sociedade geral para restringir as ações dos agentes econômicos, com finalidade do bem-estar de todos os indivíduos. Pois de acordo com Rodrigues e Oliveira (2014) Quando apenas existe um conhecimento técnico e científico não acompanhado pela conduta ética é bem provável que o campo de trabalho fique abalado. Berlatto (2015) reforça afirmando que apenas a competência profissional não basta para que a profissão seja exercida porque também deve-se assumir responsabilidades que regem cada profissão.

A ética organizacional tem por objetivo estabelecer um comportamento ético e de responsabilidade dos gestores e colaboradores perante a empresa. "o principal objetivo das empresas é obter lucro, muitas vezes deixando a ética e os valores de lado para chegar a determinadas finalidades. (BERLATTO Et. al 2015)

As correntes que defendem uma gestão ética, garantem que os benefícios para as empresas são muito grandes, proporcionando uma valorização de sua marca e, 
consequentemente, melhores resultados financeiros (Pinho Neto e Bernadi Neto 2005).

Os padrões de conduta neles estabelecidos são, de alguma forma, discutidos com os membros que compõem a respectiva classe profissional, gerando regras que devem ser respeitadas por todos. (ALVES et al, 2007).

Devido a relevância dos profissionais de contabilidade, diante a sociedade, é necessário que eles tenham uma boa reputação e uma imagem íntegra, para que os serviços fornecidos por eles, possam ser usados no momento da tomada de decisão. De acordo com Barreto (2015) o maior compromisso ético como profissional é condição fundamental para que a nossa profissão adquira credibilidade social. Conforme Bencke e Martins (2018) o profissional deve exercer e defender publicamente os princípios e valores éticos que são aplicados à classe, assim, contribuindo para uma imagem íntegra e verdadeira da profissão.

Segundo Della et al (2014) o contador tem como principal desafio adaptar-se às novas exigências do mercado, sem perder o compromisso ético que se espera de um profissional. o contador tem como principal desafio adaptar-se às novas exigências do mercado, sem perder o compromisso ético que se espera de um profissional. Freitas et.al (2011) reforça dizendo que é essencial para o profissional da Contabilidade a adesão ao conjunto de princípios éticos que sirvam de premissas para as respectivas ações.

A postura ética é fundamental no ambiente dos profissionais da contabilidade, ou seja, os contadores devem realizar suas habilidades de forma justa, consistente com a boa reputação da profissão (SILVA et. al 2015).

\subsubsection{O CÓDIGO DE ÉTICA DO PROFISSIONAL CONTÁBIL- CEPC}

Obedecer ao código de conduta identifica que o profissional haja eticamente, por seu comportamento, alcança o reconhecimento dos demais membros da própria classe e da sociedade em geral (BORGES E MEDEIROS, 2007). "O código de ética tem como 
objetivo mostrar uma conduta correta, para que os profissionais possam agir com bom senso e profissionalismo perante seus colegas" (ALVES, 2005 p.31).

Segundo Alves (2005), o CEPC surgiu mediante a aprovação do Decreto - Lei 9295/1946, no qual os Conselhos Federais e Regionais de Contabilidade, possuem a competência de examinar e penalizar, aqueles que não cumprirem o que estabelece tal normativo. Esse código tem o objetivo de "fixar a forma por que se devem conduzir os contabilistas no exercício profissional, perante seus colegas, sua classe e a sociedade", conforme destaca a Resolução do CFC № 803/96.

Recentemente houve a atualização do CEPC, que entrou em vigor, a partir de $1^{\circ}$ de junho de 2019, a NBC PG 01, segundo o CFC, a atualização foi necessária para "orientar a atuação da classe com base nesses conceitos edificados historicamente pela profissão, mas também terá o papel de conduzir as ações dos contadores conforme a realidade do século XXI". Estabelece seis capítulos, onde o primeiro trata do objetivo; em seguida Deveres, vedações e previsibilidades; Valor e publicidade dos serviços; Deveres em relação aos colegas e a classe; Penalidades e por último as Disposições gerais.

De acordo com os autores Alves (2005) e Della et al (2014) Apenas o Código de Ética do Profissional em Contabilidade não garante o exercício ético da profissão, é necessário que haja um comprometimento do profissional em agir de acordo com a verdade. Entretanto, serve para reduzir os riscos oriundos de atos antiéticos e, ao mesmo tempo, divulgar os valores das empresas, as organizações vêm implementando políticas e regras de conduta, os códigos de ética (ALVES, 2005).

Para Lisboa (1996) código de ética profissional do contador agrega como guia nas ações morais, além de possibilitar ao profissional demonstrar seus propósitos em como cumprir as regras da sociedade, respeitar a si mesmo e servir com lealdade e diligência. Segundo o mesmo autor, um dos objetivos da existência de um código de ética é auxiliar na formação ética, na constituição de uma consciência sobre regras e padrões de conduta. 
O conhecimento e aprimoramento a respeito do conteúdo destas normas possibilita a formação de profissionais contábeis conscientes de sua responsabilidade e conduz os profissionais a agirem eticamente (SILVA et al 2015). Este código instrui o contador a assumir uma postura ética de acordo com os valores admitidos pela sociedade (BERLATTO et. al. 2015).

\section{3 ÉTICA EDUCACIONAL}

A ética e a educação estão intimamente ligadas, pelo fato de a educação ser uma tentativa de conduzir a ética até o entendimento do ser humano, a fim de que este possa formar uma base moral para o aprimoramento e a qualificação profissional. (GOMES e MENDONÇA, 2016). A educação ética, é de suma relevância para os futuros profissionais, visto que através dela é possível adquirir o conhecimento dos riscos e prejuízos que atitudes desonestas poderão acarretar para a sua vida profissional, e para a de terceiros envolvidos.

De acordo com Lima et al (2015) a educação ética é considerada meio para alcançar maior percepção crítica dos estudantes. Segundo os autores Corrêa; Ferreira; Shinzaki, (2005) as universidades devem adotar como política de ensino a inclusão da disciplina Ética, e também discussões interdisciplinares sobre a importância e relevância das normas que regem uma postura íntegra e suas penalidades, na formação dos futuros contabilistas.

\subsection{ESTUDOS ANTERIORES}

Esse último tópico do referencial teórico refere-se aos estudos anteriores acerca do tema tratado, onde serviu como arcabouço teórico para desenvolver a pesquisa e alcançar os objetivos traçados.

\begin{tabular}{|l|l|l|l|l|}
\hline Ano & Autor & Título & $\begin{array}{l}\text { Objetivo da } \\
\text { Pesquisa }\end{array}$ & Resultados \\
\hline
\end{tabular}




\begin{tabular}{|c|c|c|c|c|}
\hline 2005 & Alves & $\begin{array}{l}\text { Adesão } \\
\text { contabilista } \\
\text { código de ética da } \\
\text { sua profissão: Um } \\
\text { estudo empírico } \\
\text { sobre percepções }\end{array}$ & $\begin{array}{lr}\text { Conhecer } & \text { as } \\
\text { percepções } & \text { do } \\
\text { contabilista } & \text { a } \\
\text { respeito do seu } \\
\text { Código de Ética } \\
\text { Profissional }\end{array}$ & $\begin{array}{l}\text { Cerca de } 73 \% \text { dos } \\
\text { profissionais } \\
\text { concordam } \\
\text { totalmente com a } \\
\text { afirmação de que o } \\
\text { Código } \\
\text { importante. }\end{array}$ \\
\hline 2011 & $\begin{array}{l}\text { Freitas et. } \\
\text { al. }\end{array}$ & $\begin{array}{l}\text { A percepção sobre } \\
\text { ética de estudantes } \\
\text { de curso de } \\
\text { graduação em } \\
\text { Ciências Contábeis }\end{array}$ & $\begin{array}{l}\text { Traçar a } \\
\text { percepção sobre o } \\
\text { perfil prático moral } \\
\text { e teórico moral de } \\
\text { contabilistas em } \\
\text { processo } \\
\text { formação }\end{array}$ & $\begin{array}{l}\text { Os alunos têm } \\
\text { julgamento moral } \\
\text { condizente com o } \\
\text { perfil esperado de } \\
\text { futuros profissionais, } \\
\text { sendo } \\
\text { aprendizado maior } \\
\text { para aqueles mais } \\
\text { próximos do final do } \\
\text { curso. }\end{array}$ \\
\hline 2016 & Feil et. al & $\begin{array}{l}\text { Ética profissional e } \\
\text { estudantes de } \\
\text { contabilidade: } \\
\text { análise das variáveis } \\
\text { intervenientes }\end{array}$ & 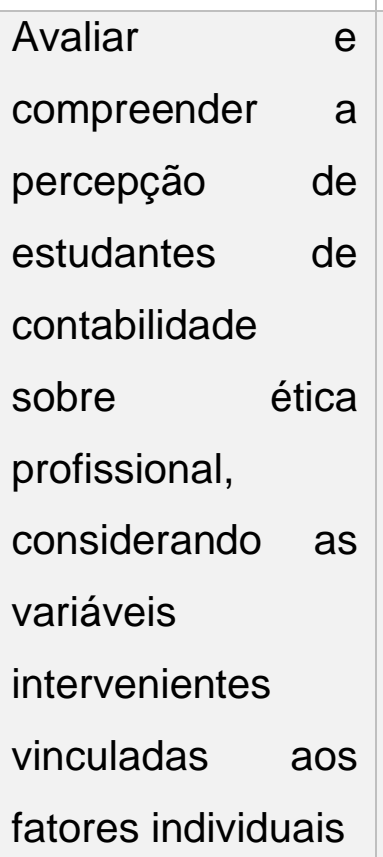 & $\begin{array}{l}\text { A existência de } \\
\text { atitudes } \\
\text { significativas é dos } \\
\text { estudantes do sexo } \\
\text { feminino, com idade } \\
\text { até } 25 \text { anos, não } \\
\text { religiosos, que } \\
\text { atuam na área } \\
\text { financeira/contábil, } \\
\text { com maturidade } \\
\text { acadêmica } \\
\text { educação ética }\end{array}$ \\
\hline 2016 & $\begin{array}{l}\text { Mendonça } \\
\text { e Gomes }\end{array}$ & $\begin{array}{l}\text { Análise } \\
\text { concepções }\end{array}$ & $\begin{array}{lr}\text { Identificar } & \text { a } \\
\text { concepção } & \text { dos }\end{array}$ & $\begin{array}{l}\text { As variáveis idade e } \\
\text { renda pessoal não }\end{array}$ \\
\hline
\end{tabular}




\begin{tabular}{|c|c|c|c|c|}
\hline & & $\begin{array}{l}\text { estudantes do curso } \\
\text { de ciências } \\
\text { contábeis acerca da } \\
\text { ética. }\end{array}$ & $\begin{array}{l}\text { graduandos do } \\
\text { curso de } \\
\text { Contabilidade de } \\
\text { uma Instituição de } \\
\text { Ensino Superior } \\
\text { (IES) do Triângulo } \\
\text { Mineiro acerca da } \\
\text { ética }\end{array}$ & $\begin{array}{l}\text { influenciaram nas } \\
\text { percepções dos } \\
\text { discentes, porém } \\
\text { foram apontadas } \\
\text { relações entre os } \\
\text { gêneros masculino e } \\
\text { feminino, quanto a } \\
\text { crença religiosa e o } \\
\text { período }\end{array}$ \\
\hline 2018 & $\begin{array}{l}\text { Bencke e } \\
\text { Martins }\end{array}$ & $\begin{array}{lr}\text { Ética geral } & \text { e } \\
\text { profissional } & \text { em } \\
\text { contabilidade: Um } \\
\text { estudo sobre a } \\
\text { postura de discentes } \\
\text { e profissionais em } \\
\text { contabilidade. }\end{array}$ & \begin{tabular}{lr}
\multicolumn{2}{l}{ Analisar a postura } \\
ética geral \\
profissional \\
adotada \\
discentes por \\
profissionais de \\
contabilidade.
\end{tabular} & $\begin{array}{l}\text { Demonstram que: } \\
\text { conhecer os } \\
\text { conceitos de ética e } \\
\text { moral não traduz e } \\
\text { não tem relação com } \\
\text { a forma de agir ético, } \\
\text { discentes } \\
\text { contadores agem de } \\
\text { forma empírica } \\
\text { quando se trata de } \\
\text { ética; }\end{array}$ \\
\hline
\end{tabular}

\section{METODOLOGIA}

No que se refere à classificação científica, quanto aos objetivos, esta pesquisa classifica-se como exploratória-descritiva. Exploratória porque objetivou, conforme a definição dada por Gil $(2009$, p.41) proporcionar maior familiaridade com o tema.

Segundo Gil (2002, p. 42):

As pesquisas descritivas têm como objetivo primordial a descrição das características de determinada população ou fenômeno ou, então, o estabelecimento de relações entre variáveis. São inúmeros os estudos 
que podem ser classificados sob este título e uma de suas características mais significativas está na utilização de técnicas padronizadas de coleta de dados, tais como o questionário e a observação sistemática.

Quanto aos meios ou procedimentos, para alcançar o objetivo proposto, classifica-se como uma pesquisa bibliográfica e de levantamento. De acordo com Raupp e Beuren (2006) os procedimentos na pesquisa científica referem-se à maneira pela qual se conduz o estudo e, portanto, se obtêm os dados. De acordo com Lakatos e Marconi (2003) a pesquisa bibliográfica é um apanhado geral sobre os principais trabalhos já realizados, revestidos de importância, por serem capazes de fornecer dados atuais e relevantes relacionados com o tema, tomou-se como base artigos, livros, dissertações e teses sobre o tema para fundamentar o referencial teórico deste trabalho.

Dessa forma, o levantamento deste trabalho foi realizado com 204 estudantes, sendo eles de 9 estados, sendo eles, Bahia, Ceará, Espírito Santo, Maranhão, Paraíba, Pernambuco, Piauí, Rio Grande do Sul e Santa Catarina, onde totaliza 3 regiões do País. Esses dados delimitou a pesquisa pela dificuldade de obter as respostas e tendo uma grande resistência de algumas instituições e alunos. Tais informações obtidas foram tratadas com a utilização de uma planilha eletrônica, através do programa Microsoft Excel, com o objetivo de tabular os dados, na medida em que foram coletados e assim facilitar a análise e discussão dos resultados.

Com relação a coleta de dados, inicialmente foi realizado um pré-teste com seis estudantes com propósito de melhorar o questionário e identificar possíveis erros, posteriormente aplicado com a amostra já citada. Tal questionário foi aplicado aleatoriamente com três mulheres e três homens, ambos discentes da universidade estadual da Paraíba. O questionário "final" foi aplicado via internet, através do Google Forms, enviado por e-mail a instituições públicas e privadas escolhidas aleatoriamente. 
Para chegar no objetivo do trabalho, o questionário foi dividido em quatro sessões, sendo o (i)- dados socioeconômicos, (ii) - Ética geral, (iii) - Ética profissional e por fim, (iv) - posicionamento ético. Nas três últimas sessões foi utilizado a escala de lickert, onde cada afirmação tinha (DT- Discordo totalmente, D- discordo, N-neutro, Cconcordo e CT-concordo totalmente), o tal foi adaptado da Tese de Doutorado desenvolvido por Alves (2005).

\section{ANÁLISE DOS RESULTADOS}

Nesta etapa, apresentam-se os resultados e discussões dos dados obtidos através da aplicação dos questionários, composta por alunos do curso de Ciências Contábeis de 9 estados. O mesmo foi dividido em quatro seções, sendo a primeira: o perfil socioeconômico dos respondentes; seguido pela seção que aborda a respeito da Ética Geral, em seguida pela parte da Ética profissional e por último trata do posicionamento ético em possíveis situações do cotidiano.

\subsection{PERFIL DOS ESTUDANTES}

Nessa seção serão demonstrados os principais resultados obtidos dos respectivos respondentes com relação às informações sócio demográficas: faixa etária, gênero, religião, tipo de instituição, estado da instituição, período que estuda, se trabalha na área contábil e se já cursou a disciplina de Ética.

A tabela 1 evidencia o gênero e a idade dos respondentes, nota-se que a maioria dos entrevistados são do gênero feminino (52\%). No estudo realizado por Martins (2018) em Santa Catarina que teve como objetivo analisar a postura ética geral e profissional adotada por discentes, observou que grande maioria também é do gênero feminino, no seu estudo, cerca de $75 \%$ dos estudantes de Ciências Contábeis são mulheres. No estudo de Antonovz et al (2010) no Paraná, revelou que cerca de $51 \%$ dos estudantes são do gênero feminino, ou seja, há mais mulheres optando por cursar Ciências Contábeis. No tocante à faixa etária dos estudantes, observa-se que a maioria destes tem entre 21 e 25 anos, que totaliza $(47,1 \%)$. 
Tabela 1 - Número de estudantes por gênero e idade

\begin{tabular}{|c|c|c|c|c|}
\hline Idade & Feminino & Masculino & Total & $\%$ \\
\hline Até 20 anos & 30 & 22 & 52 & 25,5 \\
\hline $\begin{array}{llll}\text { Entre } & 21 & \text { e } & 25 \\
\text { anos } & & & \end{array}$ & 51 & 45 & 96 & 47,1 \\
\hline $\begin{array}{llll}\text { Entre } & 26 & \text { e } & 30 \\
\text { anos } & & & \end{array}$ & 15 & 14 & 29 & 14,2 \\
\hline $\begin{array}{l}\text { Acima de } 30 \\
\text { anos }\end{array}$ & 10 & 17 & 27 & 13,2 \\
\hline Total & 106 & 98 & 204 & 100 \\
\hline$\%$ & 52 & 48 & $100 \%$ & \\
\hline
\end{tabular}

Fonte:Dados da pesquisa,2019.

O quadro 1 trata de três variáveis, no tocante a religião, 138 dos respondentes afirmaram que professa, isso é equivalente a aproximadamente $68 \%$ dos discentes. Alves (2005), no seu estudo diz que:

Um profissional que se reconheça como praticante de uma religião pode aderir ao Código pelo fato de este conter os mesmos princípios que regem a sua vida religiosa, levando-o a considerar que, por dever profissional e religioso, ele deve utilizá-lo ao se deparar com problemas éticos em seu dia-a-dia.

Observa-se também que a maioria dos respondentes não trabalham na área contábil, aproximadamente $67 \%$ destes. Se estes, aprenderem e reconhecerem a importância da Ética na profissão, tendem a serem ótimos profissionais. Quando se refere "se já cursou a disciplina de Ética" grande parte afirmou que sim, cerca de $63 \%$, essa variável muda referente a cada instituição, onde, a grade curricular das IES são diferentes. 
Quadro 1 - Religião, Trabalho e Ética

\begin{tabular}{|l|l|l|l|}
\hline Variáveis & Sim & Não & $\begin{array}{l}\text { Estou } \\
\text { cursando }\end{array}$ \\
\hline $\begin{array}{l}\text { Professa alguma } \\
\text { religião? }\end{array}$ & 138 & 66 & - \\
\hline $\begin{array}{l}\text { Trabalha na área } \\
\text { Contábil? }\end{array}$ & 69 & 135 & - \\
\hline $\begin{array}{l}\text { Já cursou a disciplina de } \\
\text { Ética? }\end{array}$ & 129 & 54 & 21 \\
\hline
\end{tabular}

Fonte: Dados da pesquisa, 2019.

O gráfico 1 refere-se ao período que os discentes estão cursando, nota-se que $15 \%$ dos respondentes estão no 4ํㅜ período, ou seja, na metade do curso. Entretanto, há universidades que o curso de Bacharel em Ciências Contábeis são 9o períodos, e pode-se observar que $10 \%$ dos graduandos que responderam o questionário estão neste período. Como dito anteriormente, a grade curricular muda de acordo com a instituição, em termos de período, disciplinas, e alocação das mesmas.

Gráfico 1 - Período que os discentes cursam

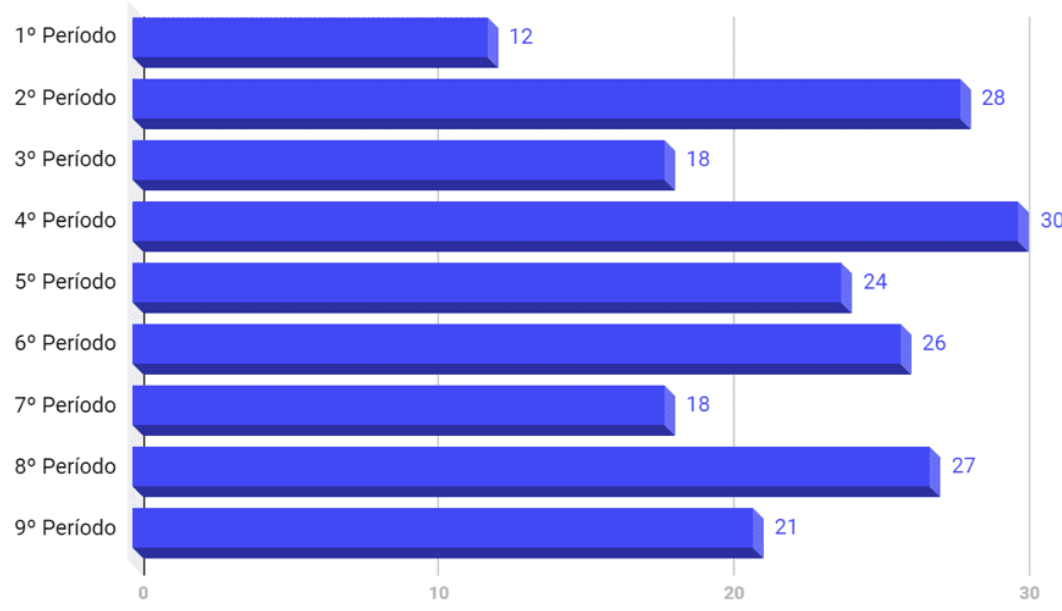

Fonte: Dados da pesquisa, 2019.

RC: 43442

Disponível em: https://www.nucleodoconhecimento.com.br/contabilidade/percepcao-da-eticacontabil 
O gráfico 2 mostra o Estado das IES que os estudantes estudam, nota-se que há uma diversidade de estados, onde totaliza 9 estados do país, esta variável relaciona diretamente com 0 gráfico 1, pois cada instituição tem sua particularidade na grade curricular, um fator relevante é a região que a IES situa-se e também outra variável que influencia diretamente é se "já cursou a disciplina de Ética" do quadro 1.

Gráfico 2 - Estado das instituições que os graduandos estudam

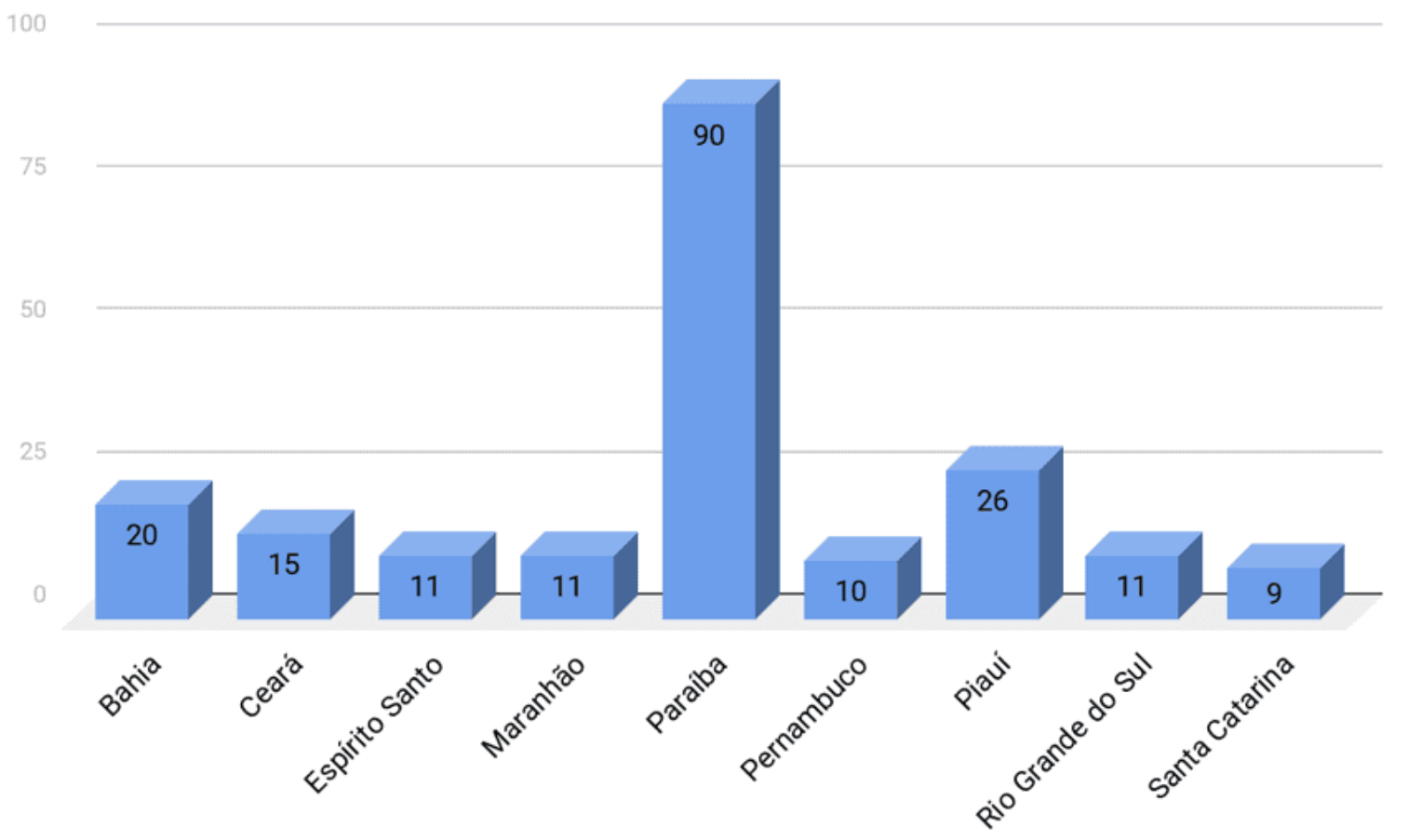

Fonte: Dados da pesquisa, 2019.

O gráfico 3 refere-se ao tipo de instituição que os respondentes estudam, pode-se notar que $91,2 \%$ dos discentes estudam em IES pública, enquanto $8,8 \%$ estudam em faculdades privadas. 
Gráfico 3 - Tipo da Instituição de Ensino Superior que os discentes estudam

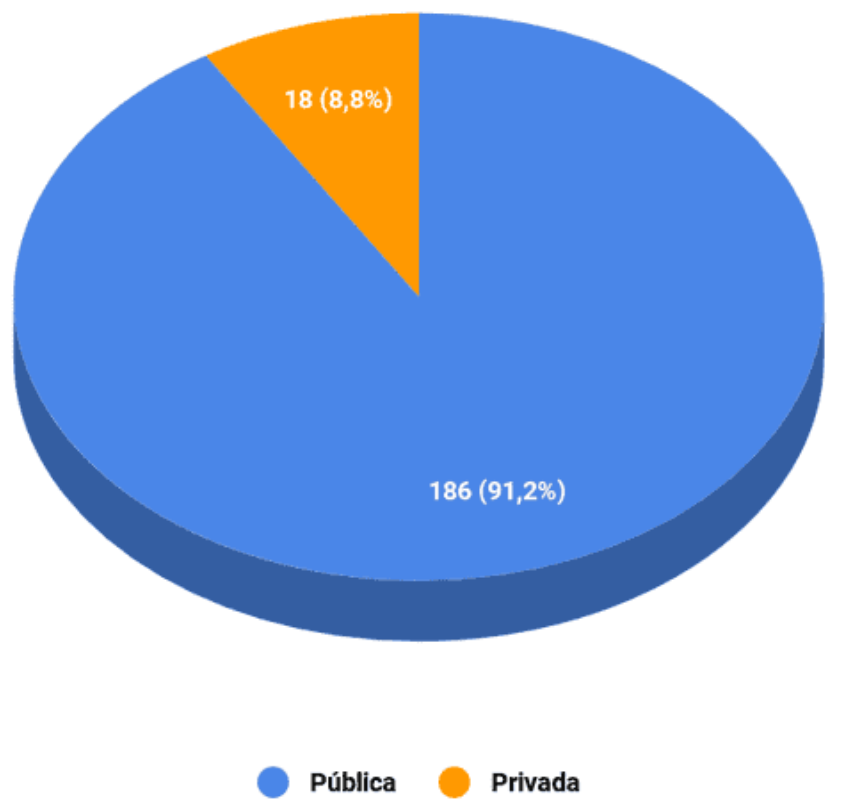

Fonte: Dados da pesquisa, 2019.

\section{2 ÉTICA GERAL}

Nesta seção foi utilizada a escala de Likert, para tabular e analisar os dados colhidos, na qual foram considerados cinco grupos, contendo os seguintes graus de concordância ou discordância (CT- concordo totalmente; C- concordo; N- neutro; Ddiscordo; DT- discordo totalmente).

O quadro 2 evidencia exemplificações da vida cotidiana, a primeira afirmação "Q7" Trata de uma situação em que mesmo a personagem percebendo que tinha recebido um valor a maior do troco devido, se calou e gastou aquele adicional para outros fins, agindo de maneira antiética, $84,3 \%$ dos respondentes concordaram totalmente com essa afirmação, e apenas 2,5\% discordaram que a pessoa foi antiética. Na afirmação "Q8" onde uma aluna tirou nota máxima em uma avaliação, mesmo sem ter estudado, realizando uma consulta no Google, para responder a avaliação, agiu de maneira 
antiética, a maioria dos respondentes, cerca de $75 \%$ concordaram totalmente com a afirmação, enquanto apenas 3,9 \% discordaram totalmente da afirmação. $\mathrm{Na}$ questão "Q9" Trouxe a afirmação que a menina foi antiética por ter mentido para os pais, dizendo que ia fazer um trabalho escolar na casa de uma colega, no entanto foi para uma festa, a maioria cerca de $50,5 \%$ dos respondentes, concordaram totalmente com a afirmação, porém 4,4 \% discordaram totalmente que a menina apresentou uma conduta antiética. E a última afirmação desta seção "Q10" que tratou sobre a utilização de vagas de pessoas deficientes no estacionamento, por uma pessoa que não apresentava nenhuma condição especial, dessa maneira ele apresentou uma conduta antiética, a maioria dos respondentes cerca de $80,4 \%$ concordaram totalmente com a afirmação, enquanto apenas 1,0 \% discordaram. Dessa maneira foi possível perceber que em todas as exemplificações que trataram sobre a ética geral, grande parte dos discentes apresentariam comportamentos positivos, portanto apresentando condutas baseadas nos princípios da ética.

Quadro 2 - Ética Geral

\begin{tabular}{|l|l|l|l|l|l|l|}
\hline $\begin{array}{l}\text { Indique o quanto você } \\
\text { concorda ou discorda de }\end{array}$ & D & N & C & CT & Total \\
uma das & $(\%)$ & $(\%)$ & $(\%)$ & $(\%)$ & $(\%)$ & $(\%)$ \\
exemplificações \\
$\begin{array}{l}\text { apresentadas a seguir. } \\
\text { Lembre-se que não existe } \\
\text { respostas certas ou } \\
\text { erradas. Marque com X }\end{array}$
\end{tabular}




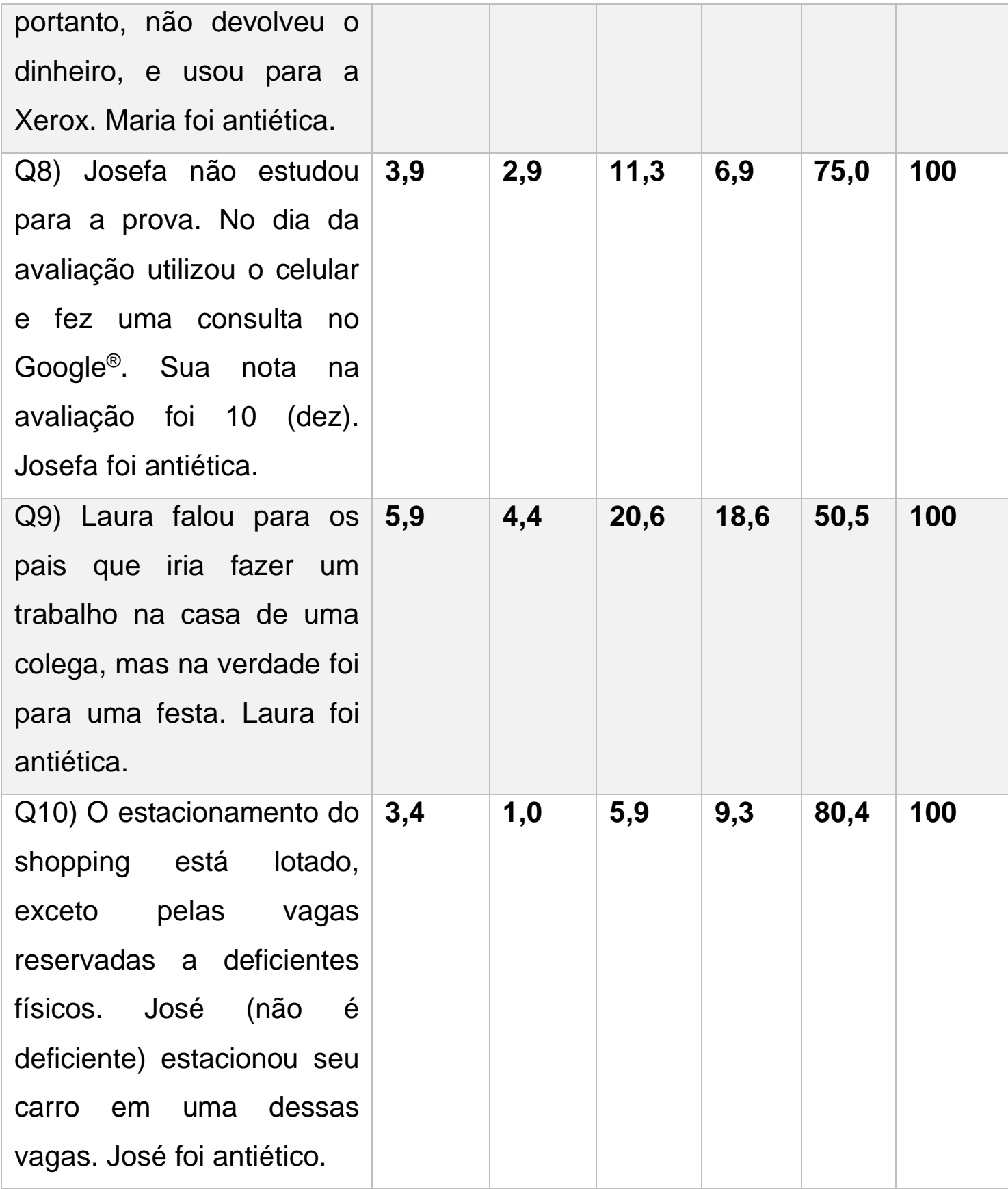

Fonte: Dados da pesquisa, 2019.

\section{3 ÉTICA PROFISSIONAL}

O quadro 3 evidencia exemplificações contendo práticas do profissional contábil, foi possível observar que os respondentes dizem que o código de ética é importante para sua carreira, $81,9 \%$ dos respondentes concordaram totalmente com o "Q11", tais 
resultados que relacionam-se com a pesquisa de Alves (2005) onde cerca de 72,82\% dos respondentes afirmaram que o CEPC é importante na sua conduta profissional. Quando confrontados com a afirmação reversa, a "Q14" os mesmos $81,9 \%$ discordaram totalmente da afirmação, e também se confirma na pesquisa de Alves, onde o mesmo achou um total de discordância de $56,59 \%$ quando refere-se que o "CEPC é irrelevante para guiar a conduta profissional". Dados desta pesquisa relacionados com de Alves, mostram que os respondentes dão importância a este código.

$\mathrm{Na}$ afirmação 12(Q12) observa-se que 52,5\% discordaram totalmente da afirmação, ou seja, eles concordam que devem seguir as normas elaborada pelo código de ética do contador. Quanto o Q13 diz que "o contador assinou documentos contábeis elaborados por outrem, sem a sua supervisão. O CRC descobriu essa atitude e o puniu com censura reservada", a maioria dos respondentes concordaram totalmente com o CRC, de acordo com o CEPC (2019) assinar documentos ou peças contábeis elaborados por outrem alheio à sua orientação, supervisão ou revisão é proibido aos contadores, sendo eles sujeito a punições, o que mostra que a maioria dos discentes questionados, estão cientes dos prejuízos, caso assinem documentos elaborados por outras pessoas, sem acompanhamento. Dessa maneira foi possível perceber que em todas as exemplificações que trataram sobre a ética profissional, grande parte dos discentes apresentariam comportamentos positivos, portanto apresentando condutas baseadas nos princípios da ética.

Quadro 3 - Ética Profissional

\begin{tabular}{|c|c|c|c|c|c|c|}
\hline $\begin{array}{l}\text { Indique o quanto você } \\
\text { concorda ou discorda de } \\
\text { cada uma das } \\
\text { exemplificações } \\
\text { apresentadas a seguir. } \\
\text { Lembre-se que não existe } \\
\text { respostas certas ou }\end{array}$ & $\begin{array}{l}\text { DT } \\
(\%)\end{array}$ & $\begin{array}{l}\text { D } \\
\text { (\%) }\end{array}$ & $\begin{array}{l}\mathrm{N} \\
(\%)\end{array}$ & $\begin{array}{l}\text { C } \\
(\%)\end{array}$ & $\begin{array}{l}\text { CT } \\
(\%)\end{array}$ & $\begin{array}{l}\text { Total } \\
(\%)\end{array}$ \\
\hline
\end{tabular}




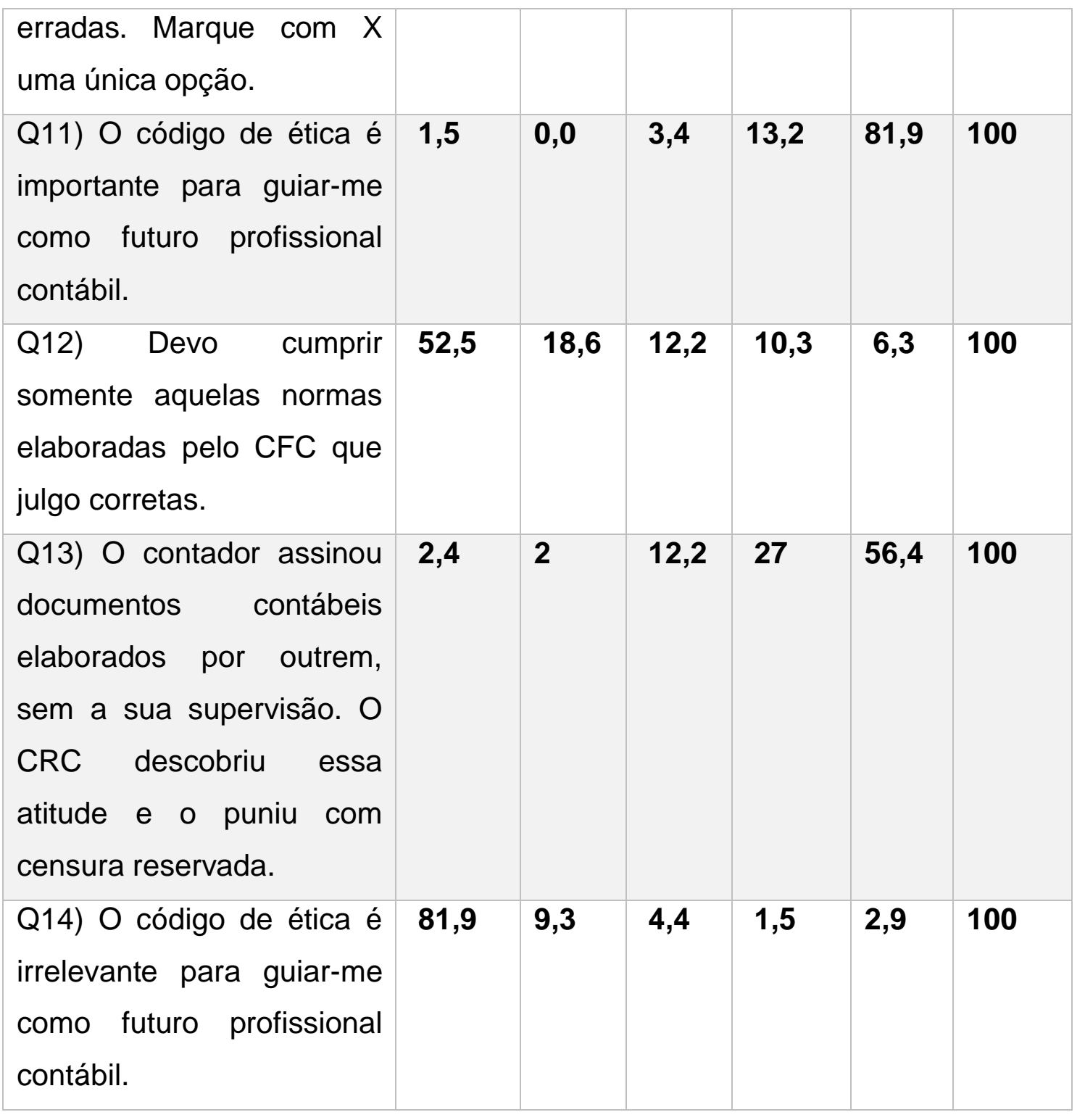

Fonte: Dados da pesquisa, 2019.

\subsection{POSICIONAMENTO ÉTICO}

O quadro 4 evidencia o posicionamento Ético de exemplificações na prática contábil, ou seja, a criticidade de se posicionar com circunstâncias antiéticas. O "Q15" referese a uma não contabilização de vendas, para diminuir o valor do imposto quando deparados com essa circunstância, $68,1 \%$ dos respondentes discordaram totalmente da atitude de João e apenas 2,5\% concordaram com a afirmação. Quanto ao "Q16" houve uma predominância por ser Neutro, pois 35,3\% dos respondentes ficaram

Disponível em: https://www.nucleodoconhecimento.com.br/contabilidade/percepcao-da-eticacontabil 
neutros nesse quesito, e apenas $7,8 \%$ dos respondentes concordaram totalmente com a afirmação. Já o "Q17" que se refere ao planejamento tributário realizado pelo contador, houve uma predominância no concordo totalmente, totalizando $63,7 \%$ dos respondentes, esse número mostra que esses discentes sabem a importância de um planejamento tributário, visto que é um conjunto de meios legais que visam diminuir a carga tributária do contribuinte. Por fim, na afirmação "Q18”, que trata do parecer do auditor, onde este encontrou irregularidades na empresa auditada e emitiu um parecer com ressalva, mesmo tendo recebido uma proposta, para apresentar seu parecer sem ressalva, agindo de maneira ética, 42,2\% dos discentes concordaram totalmente com a afirmação, no entanto cerca de 39,2 \% discordaram totalmente, pode se perceber que foi bastante parecido o número dos dois extremos, daqueles que concordaram e discordaram totalmente, apresentando uma diferença de apenas $3 \%$. Dessa maneira foi possível perceber que em todas as exemplificações que trataram sobre o posicionamento ético, a grande parte dos discentes apresentariam comportamentos positivos, portanto apresentando condutas baseadas nos princípios da ética.

Quadro 4 - Posicionamento Ético

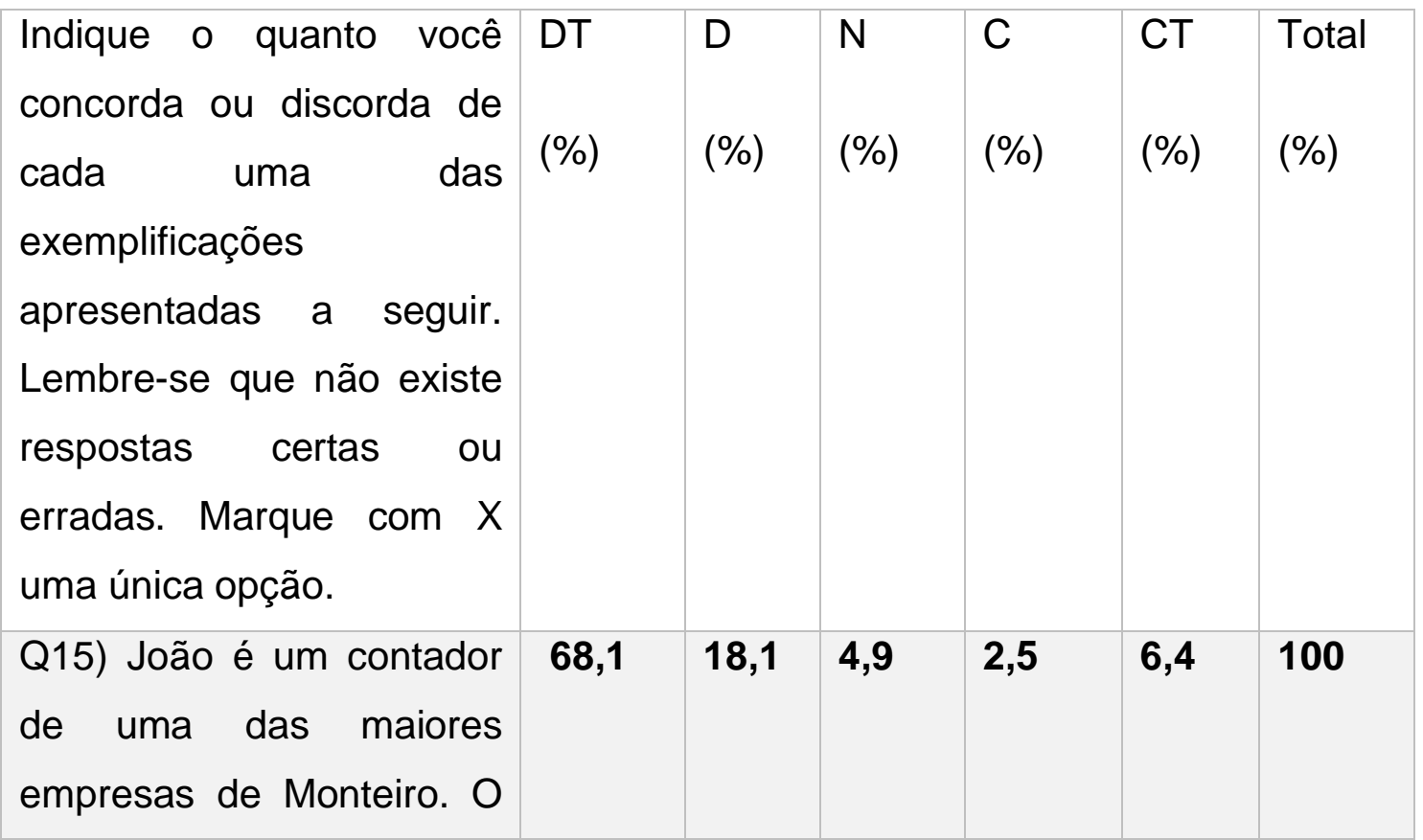




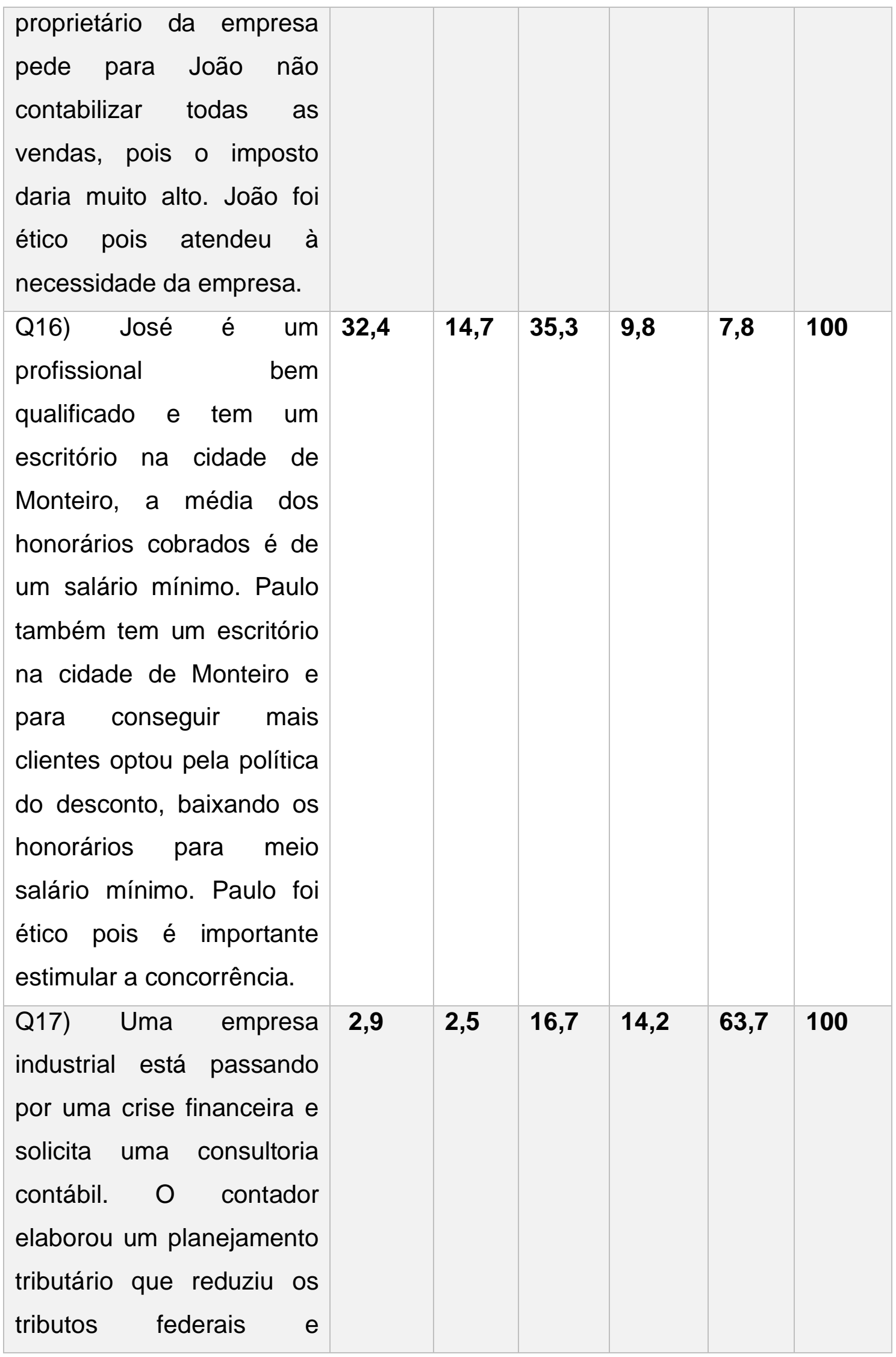

Disponível em: https://www.nucleodoconhecimento.com.br/contabilidade/percepcao-da-eticacontabil 


\begin{abstract}
estaduais. O contador foi ético pois é importante e legal 0 planejamento tributário.

Q18) A empresa Conta

Certa S.A solicitou uma auditoria externa para comprovar a veracidade de seus registros contábeis, no entanto, 0 auditor constatou que algumas guias de tributos estavam adulteradas. Ao solicitar esclarecimentos à empresa, esta lhe propôs uma gratificação significativa por um parecer sem ressalvas. $O$ auditor foi ético em emitir um parecer com ressalvas.
\end{abstract}

\begin{tabular}{|l|l|l|l|l|l|}
\hline 39,2 & 3,4 & 8,3 & 6,9 & 42,2 & 100
\end{tabular}

Fonte: Dados da pesquisa, 2019.

\title{
5. CONSIDERAÇÕES FINAIS
}

Este artigo teve como objetivo investigar a percepção que os discentes do curso de Ciências Contábeis têm sobre a Ética Contábil. Para atingir o objetivo pretendido, foi realizado um levantamento com 204 estudantes de 9 estados do país.

Nos resultados analisados, notou-se uma predominância no sexo feminino dos respondentes, também houve predominância no Estado onde a Paraíba teve mais 
respondentes e também observou que grande parte dos respondentes cursaram a disciplina de Ética, isto foi um fator relevante para os resultados obtidos.

Nos resultados analisados, observou-se que os discentes percebem a importância da Ética para sua futura profissão, e que há de se considerar que os mesmos dão importância ao código de ética do contador. Analisou-se que grande parte dos discentes quando deparados com exemplificações do cotidiano agiriam de forma ética na maioria dos casos.

Destaca-se que este estudo mostrou resultados importantes e aumenta as oportunidades de novas pesquisas na área de Ética, para pesquisas futuras indica-se realizar um estudo com os profissionais de Contabilidade e posterior fazer um comparativo entre discentes e profissionais.

\section{REFERÊNCIAS}

ALVES, Francisco José dos Santos. A adesão do contabilista ao código de ética da sua profissão: um estudo empírico sobre percepções. 2005. Tese de Doutorado. Universidade de São Paulo.

ANTONOVZ, Tatinae, et al. Atitudes éticas dos contadores: evidências recentes de uma pesquisa com alunos e profissionais contábeis sob a perspectiva de gênero. Revista de Contabilidade e Organizações, 2010, 4.10: 86-105.

BARRETO, L. M. S. F. Formação ética do profissional de contabilidade. Revista Eletrônica da FANESE, v. 4, n. 1, p. 1-14, 2015.

BERLATTO, Odir et al. As contribuições da ética ao profissional da contabilidade. Revista de Gestão e Contabilidade da UFPI, v. 2, n. 1, 2015.

BORGES, Erivan; MEDEIROS, Carlos. Comprometimento e ética profissional: um estudo de suas relações junto aos contabilistas. 2007. 
BRASIL. Decreto - LEI No 9.295, 27 DE MAIO DE 1946. Disponível em: <http://www.planalto.gov.br/ccivil_03/Decreto-Lei/Del9295.htm>. Acesso em 30 de jun de 2019.

CÓDIGO DE ÉTICA PROFISSIONAL DO CONTADOR É ATUALIZADO: SAIBA O QUE MUDOU. Disponívelem:<https://cfc.org.br/noticias/codigo-de-etica-profissionaldo-contador-e-atualizado-saiba-o-que-mudou/>. Acesso em 19/07/2019.

CRUZ, Felipe Rodrigues et al. TRÊS VISÕES SOBRE ÉTICA E EVASÃO FISCAL: COMO SE POSICIONAM OS ESTUDANTES DA ÁREA DE NEGÓCIOS? Revista Universo Contábil, v. 14, n. 2, p. 82-99, 2019.

DOS SANTOS ALVES, Francisco José et al. Um estudo empírico sobre a importância do código de ética profissional para o contabilista. Revista Contabilidade \& Finanças, v. 18, p. 58-68, 2007.

DA SILVA, Antonia Rosane Nascimento; DE FIGUEIREDO, Sandra Maria Aguiar. Desenvolvimento da percepção sobre Ética Profissional entre estudantes de contabilidade. Revista Brasileira de Contabilidade, n. 165, p. 40-51, 2012.

DE FREITAS, Andréia Ciryno; DIEHL, Carlos Alberto; MACAGNAN, Clea Beatriz. A percepção sobre ética de estudantes de curso de graduação em Ciências Contábeis. Revista de Educação e Pesquisa em Contabilidade, v. 5, n. 1, p. 21-49, 2011.

DELLA, Flora Vianna Andrieli et al. Ética no horizonte do profissional contábil. Revista Interdisciplinar de Ensino, Pesquisa e Extensão, v. 2, n. 1, 2015.

DE OLIVEIRA, Nathalia Gil; RODRIGUES, Wilson Medeiros. Conflitos éticos no exercício da profissão contábil. Revista Eletrônica do Curso de Ciências Contábeis, v. 3, n. 4, p. 165-187, 2014. 
DOS ANJOS, Luiz Carlos Marques et al. Código de Ética e o Comportamento ético na vida pessoal: um estudo junto a pessoas envolvidas com a Contabilidade. Revista de Contabilidade da UFBA, v. 5, n. 2, p. 4-19, 2011.

FEIL, Alexandre André; DIEHL, Liciane; SCHUCK, Rogério José. Ética profissional e estudantes de contabilidade: análise das variáveis intervenientes. Cadernos EBAPE. BR, v. 15, n. 2, p. 256-273, 2017.

GIL, Antônio Carlos. Como elaborar projetos de pesquisa. São Paulo, v. 5, n. 61, p. 16-17, 2002.

GIL, A. C. Como elaborar projetos de pesquisa. 6 ed. São Paulo: Atlas, 2008.

GOMES, Fabrício Pereira; ARAÚJO, Richard Medeiros de. Pesquisa QuantiQualitativa em Administração: uma visão holística do objeto em estudo. Seminários em Administração, v. 8, p. 1-11, 2005.

LAKATOS, E. M. de A.; MARCONI, M. de A. Fundamentos da metodologia científica. São Paulo: Atlas, 2003.

LISBOA, L. P. Ética geral e profissional em contabilidade / Fundação Instituto de Pesquisas Contábeis, Atuariais e Financeiras; direção geral Eliseu Martins - 2 ed. São Paulo: Atlas, 1997. 7a reimpressão, FIPECAFI, 2006.

LISBOA, Lázaro Plácido. Ética Geral e Profissional em Contabilidade. São Paulo: Saraiva, 1996.

LIMA, Maria Eduarda Barbosa et al. Ética em contabilidade: um estudo sobre a percepção dos discentes acerca da ética profissional. Revista de Gestão e Contabilidade da UFPI, v. 1, n. 2, 2015.

LISBOA, L. P. Ética geral e profissional em contabilidade / Fundação Instituto de Pesquisas Contábeis, Atuariais e Financeiras; direção geral Eliseu Martins - 2 ed. São Paulo: Atlas, 1997. 7a reimpressão, FIPECAFI, 2006. 
LISBOA, Lázaro Plácido. Ética Geral e Profissional em Contabilidade. São Paulo: Saraiva, 1996.

MENDONÇA, Wesley Sidney; GOMES, Gilvania Sousa. Análise das concepções dos estudantes do curso de ciências contábeis acerca da ética. RAGC, v. 4, n. 15, 2016.

LISBOA, Lazaro Plácido et al. Ética Geral e Profissional em Contabilidade. 2. ed. São Paulo: Atlas, 1997.

MARTINS, Patricia Jung; BENCKE, Fernando Fantoni. ÉTICA GERAL E PROFISSIONAL EM CONTABILIDADE: UM ESTUDO SOBRE A POSTURA DE DISCENTES E PROFISSIONAIS EM CONTABILIDADE. Revista de Contabilidade da UFBA, v. 12, n. 2, p. 150-165, 2018.

MENDONÇA, Wesley Sidney; GOMES, Gilvania Sousa. Análise das concepções dos estudantes do curso de ciências contábeis acerca da ética. RAGC, v. 4, n. 15, 2016.

OLIVEIRA, A. P.; ORÇO, C. L.; GUIDANI E. R.; I. B. Ética e sociedade - Joaçaba: Unoesc Virtual, 2010.

RAUPP, Fabiano Maury; BEUREN, Ilse Maria. Metodologia da Pesquisa Aplicável às Ciências. Como elaborar trabalhos monográficos em contabilidade: teoria e prática. São Paulo: Atlas, 2006.

VÁSQUEZ, Adolfo Sánchez. Ética. 11. ed. Rio de Janeiro: Civilização Brasileira. 1987.

SILVA, Cinara Núbia et al. NORMAS ÉTICAS-DISCIPLINARES DA PROFISSÃO CONTÁBIL: UMA INVESTIGAÇÃO DA PERCEPÇÃO DOS ACADÊMICOS EM CIÊNCIAS CONTÁBEIS DE UBERLÂNDIA. Revista Ciências Sociais em Perspectiva, v. 14, n. 27, p. 178-201.

Enviado: Dezembro, 2019.

Aprovado: Janeiro, 2020. 